\title{
Curcumin potentiates the effect of chemotherapy against acute lymphoblastic leukemia cells via downregulation of $\mathrm{NF}-\kappa \mathrm{B}$
}

\author{
HELIA JUDITH PIMENTEL-GUTIÉRREZ ${ }^{1,2}$, LUCINA BOBADILLA-MORALES ${ }^{1,2}$, \\ CÉSAR CENOBIO BARBA-BARBA ${ }^{2}$, CITLALLI ORTEGA-DE-LA-TORRE ${ }^{2}$, \\ FERNANDO ANTONIO SÁNCHEZ-ZUBIETA ${ }^{2}$, JORGE ROMÁN CORONA-RIVERA ${ }^{1,2}$, \\ BETSY ANNEL GONZÁLEZ-QUEZADA ${ }^{1}$, JUAN S. ARMENDÁRIZ-BORUNDA ${ }^{3}$, \\ ROCÍO SILVA-CRUZ ${ }^{1}$ and ALFREDO CORONA-RIVERA ${ }^{1,2}$
}

\begin{abstract}
${ }^{1}$ Cytogenetics, Genotoxicity and Biomonitoring Laboratory, Human Genetic Institute 'Dr. Enrique Corona Rivera', PhD Program in Molecular Biology, Health Sciences University Center, University of Guadalajara; ${ }^{2}$ Cytogenetics Unit, Pediatric Hematology and Oncology Service, Pediatric Division, Civil Hospital of Guadalajara;

${ }^{3}$ Molecular Biology and Gene Therapy Institute, Health Sciences University Center, University of Guadalajara, Guadalajara, Jalisco 44340, México
\end{abstract}

Received November 11, 2015; Accepted May 16, 2016

DOI: $10.3892 / \mathrm{ol} .2016 .5217$

\begin{abstract}
Acute lymphoblastic leukemia (ALL) accounts for $30 \%$ of all pediatric cancers. Currently available treatments exhibit toxicity and certain patients may develop resistance. Thus, less toxic and chemoresistance-reversal agents are required. In the present study, the potential effect of curcumin, a component of Curcuma longa, as a pharmacological co-adjuvant of several chemotherapeutic agents against ALL, including prednisone, 6-mercaptopurine, dexamethasone, cyclophosphamide, l-asparaginase, vincristine, daunorubicin, doxorubicin, methotrexate and cytarabine, was investigated in the REH ALL cell line cultures treated in combination with chemotherapeutic agents and curcumin. The results of cell viability, gene expression and activation of NF- $\mathrm{\kappa B}$ and caspase 3 indicated that curcumin potentiates the anticancer effects of the aforementioned chemotherapeutic agents in the REH ALL cell line. Following treatment with the above chemotherapeutic agents, curcumin enhanced caspase- 3 activation and downregulated nuclear factor-kappa B (NF-кB) activation. Curcumin also downregulated the oxidative stress induced by certain chemotherapies. Notably, curcumin did not affect the gene expression of cell survival proteins such as B-cell lymphoma (Bcl)-2, Bcl-extra large, survivin, c-Myc and cyclin D1, which are regulated by the NF- $\mathrm{kB}$ transcription
\end{abstract}

Correspondence to: Dr Alfredo Corona-Rivera, Cytogenetics, Genotoxicity and Biomonitoring Laboratory, Human Genetic Institute 'Dr. Enrique Corona Rivera', Health Sciences University Center, University of Guadalajara, 950 Sierra Mojada Street, Guadalajara, Jalisco 44340, México

E-mail: alcoronar@gmail.com

Key words: chemotherapy, curcumin, leukemia, NF-кB factor. In conclusion, curcumin has the potential to improve the effect of chemotherapeutic agents against ALL.

\section{Introduction}

Acute lymphoblastic leukemia (ALL) is one of the most malignant types of hematological disease, which accounts for $30 \%$ of all pediatric cancers (1). Chemotherapeutic drugs commonly used for ALL treatment include prednisone, 6-mercaptopurine, dexamethasone, cyclophosphamide, 1-asparaginase, vincristine, daunorubicin or doxorubicin, methotrexate and cytarabine; with overall cure rates of $80 \%$ (Fig. 1) (2). However, a significant number of patients develop resistance to these drugs and outcome is poor among patients who relapse (2). The pathogenesis of ALL includes changes in gene expression, which are regulated by diverse transcription factors (3) such as nuclear factor-kappa B (NF- $\mathrm{BB}$ ), which has been associated with cell proliferation and survival (4). Additionally, in solid tumors, NF- $\kappa \mathrm{B}$ exhibits an important function in invasion, angiogenesis, aggressive tumor growth and chemoresistance (4-6). Constitutive activation of NF- $\mathrm{KB}$ is observed in $~ 92 \%$ of pediatric ALL patients (7) and thus is one of the targets for chemosensitization.

Since $\sim 80 \%$ of clinical drugs are derived from natural products, numerous compounds have been identified that downmodulate NF-kB (8). Curcumin (diferuloylmethane), a polyphenol derived from the plant Curcuma longa, has been demonstrated to inhibit NF- $\mathrm{kB}$ activation, which is induced by a wide variety of carcinogens and chemotherapeutic agents (9). The use of curcumin was classified by the USA Food and Drug Administration as 'generally recognized as safe' (10). Furthermore, various clinical trials indicate that curcumin may be administered at oral doses as high as $8 \mathrm{~g} /$ day with no side effects (11).

The aim of the present study was to investigate the potential anticancer effect of curcumin on the human REH ALL cell line, 
when administered alone and in combination with currently used therapies. The results indicate that curcumin potentiates the effect of chemotherapeutic agents against ALL cells by activation of caspase-3 through downregulation of oxidative stress, $\mathrm{NF}-\kappa \mathrm{B}$ activation and various $\mathrm{NF}-\kappa \mathrm{B}-$ regulated cell survival gene products.

\section{Materials and methods}

Reagents. Curcumin and sodium dodecyl sulfate were obtained from Sigma-Aldrich (St. Louis, MO, USA). Penicillin, streptomycin, RPMI-1640 medium, phosphate-buffered saline (PBS), fetal bovine serum (FBS) and TaqMan Assays for B-cell lymphoma (Bcl)-extra large (xL), Bcl-2, cyclin D1, survivin, c-Myc and beta-glucuronidase (GUSB) were obtained from Life Technologies (Thermo Fisher Scientific, Inc., Waltham, MA, USA). DNA and RNA extraction was performed using QIAzol Lysis reagent and QIAmp Circulating Nucleic Acid kit, which were obtained from Qiagen $\mathrm{GmbH}$ (Hilden, Germany). Monoclonal anti-NF- $\mathrm{B}$ (dilution, 1:50; cat. no. A88940), anti-cluster of differentiation (CD)45 (dilution, 1:10; cat. nos. IM2652U and IM0782U) and anti-caspase-3 (dilution, 1:50; cat. no. A88950) antibodies, 7-aminoactinomycin D (7-AAD) viability dye, PerFix EXPOSE Phospho-Epitopes Exposure kit and IntraPrep ${ }^{\mathrm{TM}}$ permeabilization reagent were obtained from Beckman Coulter, Inc. (Brea, CA, USA). Anti-NF- $\kappa$ B p65 antibody (dilution, $1 \mu \mathrm{g}$; cat. no. sc-8008) was obtained from Santa Cruz Biotechnology, Inc. (Dallas, TX, USA). Highly sensitive 8-hydroxy-2'-deoxyguanosine (8-OHdG) was supplied by the Japanese Institute for the Control of Aging (Fukuroi, Japan). Prednisone, 6-mercaptopurine, dexamethasone, cyclophosphamide, l-asparaginase, vincristine, daunorubicin, doxorubicin, methotrexate and cytarabine were provided by PiSA Farmacéutica (Guadalajara, México).

Cell culture. The REH cell line (St. Jude Children's Research Hospital, Memphis, TN, USA) was cultured in RMPI-1640 medium supplemented with $100 \mathrm{U} / \mathrm{ml}$ penicillin and $100 \mathrm{~g} / \mathrm{ml}$ streptomycin with $10 \% \mathrm{FBS}$ in a humidified incubator at $37^{\circ} \mathrm{C}$ with an atmosphere of $5 \% \mathrm{CO}_{2}$. Next, $5 \times 10^{5} \mathrm{REH}$ cells were treated for $48 \mathrm{~h}$ in triplicate with $125 \mu \mathrm{g} / \mathrm{ml}$ prednisone, $250 \mu \mathrm{g} / \mathrm{ml}$ 6-mercaptopurine, $0.4 \mu \mathrm{g} / \mathrm{ml}$ dexamethasone, $50 \mu \mathrm{g} / \mathrm{ml}$ cyclophosphamide, $5 \mathrm{U}$ l-asparaginase, $25 \mu \mathrm{g} / \mathrm{ml}$ vincristine, $1 \mu \mathrm{g} / \mathrm{ml}$ daunorubicin, $0.5 \mu \mathrm{g} / \mathrm{ml}$ doxorubicin, $7.5 \mu \mathrm{g} / \mathrm{ml}$ methotrexate and $1.25 \mu \mathrm{g} / \mathrm{ml}$ cytarabine, with or without $20 \mu \mathrm{M}$ curcumin. Untreated cells served as the control group.

Viability assay. Cell viability was determined by flow cytometry using a 7-AAD dye exclusion test. After treatment with the various drugs, cells were harvested, washed once in PBS and centrifuged at $100 \mathrm{x} \mathrm{g}$ at room temperature for $1 \mathrm{~min}$, and incubated with $100 \mu \mathrm{l}$ PBS, $20 \mu \mathrm{l}$ anti-CD45-FITC (dilution, 1:10; cat. no. IM0782U; Beckman Coulter, Inc.) and $100 \mu \mathrm{l}$ 7-AAD for $20 \mathrm{~min}$ at room temperature in the dark. Following incubation, the cells were suspended in PBS and 20,000 events were analyzed using a Gallios Flow Cytometer (Beckman Coulter, Inc.). Gating was set to exclude cell debris and autofluorescence.
DNA oxidation. To determine if curcumin prevents oxidative damage to DNA caused by chemotherapy treatment, oxidative DNA adducts were measured using the highly sensitive 8-OHdG. DNA was isolated from the cells using QIAamp DNA Mini kit (Qiagen $\mathrm{GmbH}$ ) and mixed with $50 \mu \mathrm{l}$ nuclease-free water. Later, the cells were digested with Mung Bean Nuclease (6 U; Promega, Madison, WI, USA) at $37^{\circ} \mathrm{C}$ for $45 \mathrm{~min}$, followed by treatment with alkaline phosphatase $(2 \mathrm{U})$ for an additional $45 \mathrm{~min}$. DNA was precipitated with absolute ethanol and centrifuged at 2,370 x g for $2 \mathrm{~min}$, followed by hydration with $50 \mu 1$ nuclease-free water. The digested DNA was added to the 8-OHdG (Highly Sensitive 8-OHdG Check ELISA kit; cat. no. KOG-HS10E; Japan Institute for the Control of Aging, Fukuroi, Japan.) well strip and incubated with $50 \mu \mathrm{l}$ primary monoclonal antibody (dilution, $1 \mu \mathrm{g} / 50 \mu \mathrm{l}$ ) specific for $8-\mathrm{OHdG}$ at $4{ }^{\circ} \mathrm{C}$ overnight. Following incubation, 3 washes were performed with $250 \mu \mathrm{l}$ washing solution (Japanese Institute for the Control of Aging) at room temperature, with agitation of the plate from side to side for 20 seconds, disposing washing solution each time. The samples were then incubated with $50 \mu 1$ horseradish peroxidase-conjugated antimouse secondary antibody (dilution, $1 \mu \mathrm{g} / 5 \mu \mathrm{l}$; cat. no. 405310) for $1 \mathrm{~h}$ at room temperature in the dark. After 3 washes, $50 \mu \mathrm{l}$ chromatic solution (Japanese Institute for the Control of Aging) was added and incubated for $15 \mathrm{~min}$ at $4^{\circ} \mathrm{C}$. The reaction was terminated following addition of $100 \mu 1$ termination solution (Japanese Institute for the Control of Aging), and the samples were analyzed at a wavelength of $450 \mathrm{~nm}$ in a plate spectrophotometer.

$N F-\kappa B$ detection. To assess the involvement of curcumin in $\mathrm{NF}-\kappa \mathrm{B}$ activation, flow cytometry was performed using anti-human-phospho-NF- $\mathrm{B}$ p65 antibody (Beckman Coulter, Inc.). After the treatment the cells were fixed using PerFix Fixative reagent (Beckman Coulter, Inc.) for $10 \mathrm{~min}$ at room temperature and permeabilized using PerFix Permeabilizing reagent for $5 \mathrm{~min}$ at $37^{\circ} \mathrm{C}$ in a water bath (PerFix EXPOSE Phospho-Epitopes Exposure kit; Beckman Coulter, Inc.). A total of $50 \mu \mathrm{l}$ staining reagent pre-mixed with $2 \mu \mathrm{l}$ conjugated anti-NF-кB-AlexaFluor 647 (dilution, 1:50; cat. no. A88940; Beckman Coulter, Inc.) and $10 \mu \mathrm{l}$ anti-CD45-FITC antibodies were added to each tube immediately and incubated at room temperature for $30 \mathrm{~min}$ in the dark. Cells were then washed with $3 \mathrm{ml} 1 \mathrm{X}$ wash reagent (PerFix EXPOSE; Beckman Coulter, Inc.) at room temperature, centrifuged at $300 \mathrm{x} \mathrm{g}$ for $5 \mathrm{~min}$. The washing solution was removed and the cells were suspended in $500 \mu \mathrm{l}$ final $1 \mathrm{X}$ reagent (PerFix EXPOSE; Beckman Coulter, Inc.), and 20,000 events were analyzed using Gallios software version 10 (Beckman Coulter, Inc.). Gating was set to exclude cell debris and autofluorescence.

Gene expression. To determine changes in the expression of various genes that are downregulated by $\mathrm{NF}-\kappa \mathrm{B}, \mathrm{RNA}$ extraction was performed using QIAzol Lysis reagent. The cells were washed with PBS at room temperature, centrifuged at $100 \mathrm{x} g$ for $2 \mathrm{~min}$ at room temperature and incubated with $1 \mathrm{ml} \mathrm{QIAzol}$ Lysis reagent for $5 \mathrm{~min}$, followed by the addition of $200 \mu \mathrm{l}$ chloroform and centrifugation at $12,350 \mathrm{x} \mathrm{g}$ at $4^{\circ} \mathrm{C}$ for $10 \mathrm{~min}$. The aqueous phase was recovered in $500 \mu \mathrm{l}$ isopropanol and incubated at $-20^{\circ} \mathrm{C}$ overnight. Next, samples were centrifuged at 
$12,350 \mathrm{x}$ g at $4^{\circ} \mathrm{C}$ for $10 \mathrm{~min}$ and washed twice with $70 \%$ ethanol, with centrifugation performed at $9,680 \times \mathrm{g}$ at $4^{\circ} \mathrm{C}$ for $5 \mathrm{~min}$ between each wash, and then air dried for $30 \mathrm{~min}$. The samples were reconstituted in $30 \mu \mathrm{l}$ diethylpyrocarbonate-treated water (Invitrogen; Thermo Fisher Scientific, Inc.). Reverse transcription was performed using $1 \mu \mathrm{g}$ total RNA and a High-Capacity cDNA Reverse Transcription kit (Applied Biosystems; Thermo Fisher Scientific, Inc.) in a GeneAmp PCR System 9700 thermal cycler (Applied Biosystems; Thermo Fisher Scientific, Inc.). The reaction conditions were as follows: $25^{\circ} \mathrm{C}$ for $25 \mathrm{~min}, 37^{\circ} \mathrm{C}$ for $120 \mathrm{~min}, 85^{\circ} \mathrm{C}$ for $5 \mathrm{~min}$ and infinite hold at $4^{\circ} \mathrm{C}$. Quantitative polymerase chain reaction (PCR) was performed using TaqMan Assays for the different genes and the TaqMan Universal PCR Master Mix (Applied Biosystems; Thermo Fisher Scientific, Inc.) in a 7900HT Fast Real-Time PCR System using SDS 2.4 software (Applied Biosystems; Thermo Fisher Scientific, Inc.). PCR was performed according to the manufacturer's protocol, and the cycling conditions were as follows: $50^{\circ} \mathrm{C}$ for $2 \mathrm{~min}, 95^{\circ} \mathrm{C}$ for $10 \mathrm{~min}, 95^{\circ} \mathrm{C}$ for $15 \mathrm{sec}$ and $60^{\circ} \mathrm{C}$ for $1 \mathrm{~min}$ (40 cycles). Data was quantified according to the relative quantitation $2^{-\Delta \Delta \mathrm{Cq}}$ method (12), using the GUSB gene as an endogenous control and the chemotherapy treatment groups without curcumin as a calibrator (13).

Caspase-3 detection. To determine whether curcumin potentiates caspase-3 activity, flow cytometry was performed using polyclonal anti-human cleaved caspase-3 (Asp-175). The cells $\left(5 \times 10^{5}\right)$ were mixed with $20 \mu 1$ anti-CD45-PC5 (dilution, 1:10; cat. no. IM2653U; Beckman Coulter, Inc.) and incubated for $20 \mathrm{~min}$ at room temperature in the dark. Cells were fixed using $100 \mu \mathrm{l}$ IntraPrep Fixation reagent (Beckman Coulter, Inc.) for $15 \mathrm{~min}$ at room temperature, washed in $4 \mathrm{ml}$ PBS and centrifuged at $300 \mathrm{x}$ g for $5 \mathrm{~min}$. Subsequent to washing, the cells were permeabilized for $5 \mathrm{~min}$ at room temperature using IntraPrep ${ }^{\mathrm{TM}}$ Permeabilization reagent (Beckman Coulter, Inc.). Next, the cells were incubated with $2 \mu \mathrm{l}$ polyclonal anti-human cleaved caspase-3 (Asp-175) for $45 \mathrm{~min}$ at room temperature in the dark. The cells were then washed and suspended in $500 \mu 1$ PBS and 20,000 events were analyzed using Gallios software version 10 (Beckman Coulter, Inc.). Gating was set to exclude cell debris and autofluorescence.

Statistical analysis. Differences in various parameters were compared in the control and treatment groups using the PASW 18.0 Software (SPSS, Inc., Chicago, IL, USA). The data were firstly analyzed using the Kolmogorov-Smirnov test. When the data had a normal distribution, the groups were compared using the Student's t-test. When the distribution did not have a normal distribution, the data were analyzed using Mann-Whitney $\mathrm{U}$ test. $\mathrm{P}<0.05$ was considered to indicate a statistically significant difference.

\section{Results}

The antitumor properties of curcumin have been evaluated in a large number of solid tumors (14), however, less is known regarding hematological neoplasias.

Curcumin decreases cell viability of REH cells. To evaluate the effect of curcumin alone on cell viability, flow cytometry

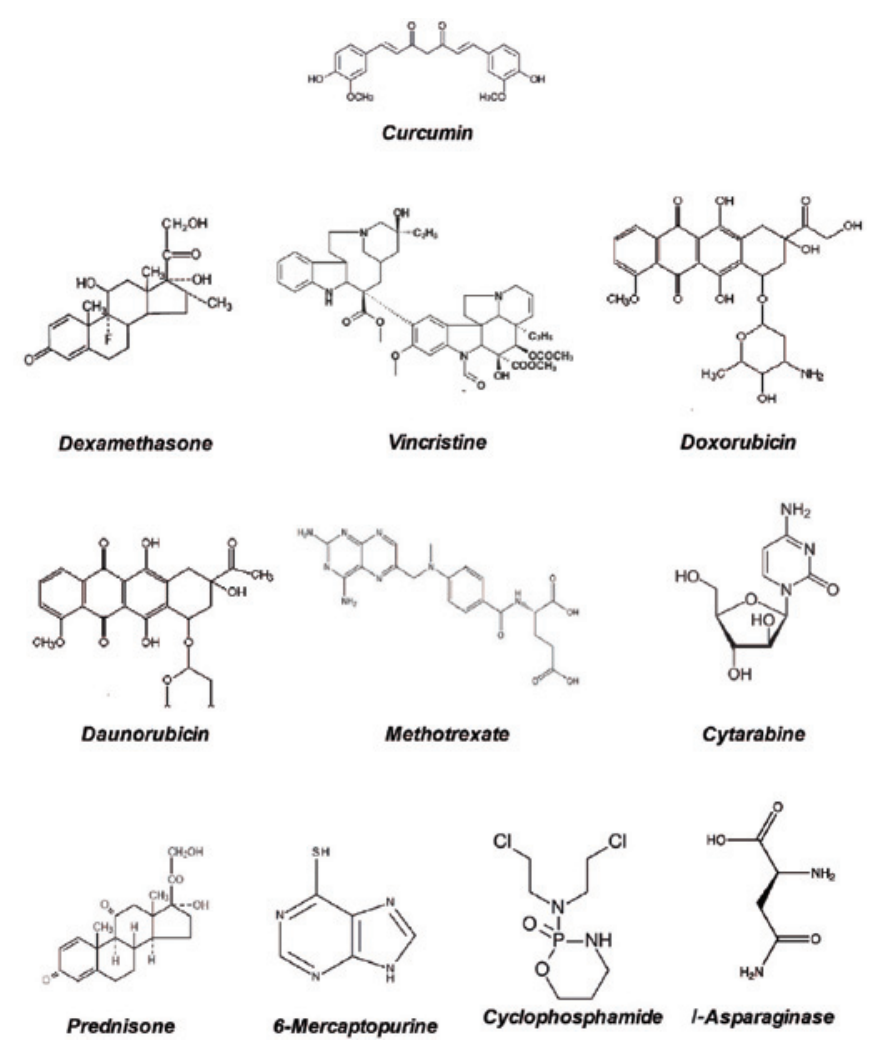

Figure 1. Chemical structures of curcumin and the 10 chemotherapeutic agents used in the present study.

was performed using 7-AAD. To determine the effect of curcumin on the viability of REH cells, six different concentrations were investigated $(10,20,25,30,40$ and $50 \mu \mathrm{M})$. Curcumin decreased cell viability in a dose-dependent manner in REH cells, and following treatment with 25, 30, 40 and $50 \mu \mathrm{M}$ curcumin, the cell viability was significantly decreased when compared with the control $(\mathrm{P}<0.001)$. A dose of $20 \mu \mathrm{M}$ curcumin was selected for further experiments, as the next tested dose of $25 \mu \mathrm{M}$ curcumin had statistical differences in cell viability compared with the control group from a pilot study.

Combined treatment with chemotherapeutic agents and curcumin decreases cell viability in REH cells. 7-AAD flow cytometry was performed to investigate whether curcumin potentiates the effect of chemotherapeutic agents and decreases the cell viability of REH cells. The results revealed that treatment with all chemotherapeutic agents reduced cell viability when compared with the control. Furthermore, combined treatment with curcumin resulted in a further decrease in cell viability for all chemotherapeutic drugs (Fig. 2A). The group treated with curcumin alone exhibited a cell viability of $86.3 \%$, whereas the group treated with l-asparaginase alone exhibited a cell viability of $89.7 \%$. Notably, combined treatment with 1-asparaginase and curcumin decreased cell viability to $59.9 \%$ (Fig. 2B). The same potentiating effect of curcumin was observed with prednisone, cyclophosphamide, 6-mercaptopurine, dexamethasone, vincristine and methotrexate $(\mathrm{P}<0.05)$.

Curcumin prevents DNA oxidation. It has been demonstrated that chemotherapeutic agents induce DNA damage in normal 

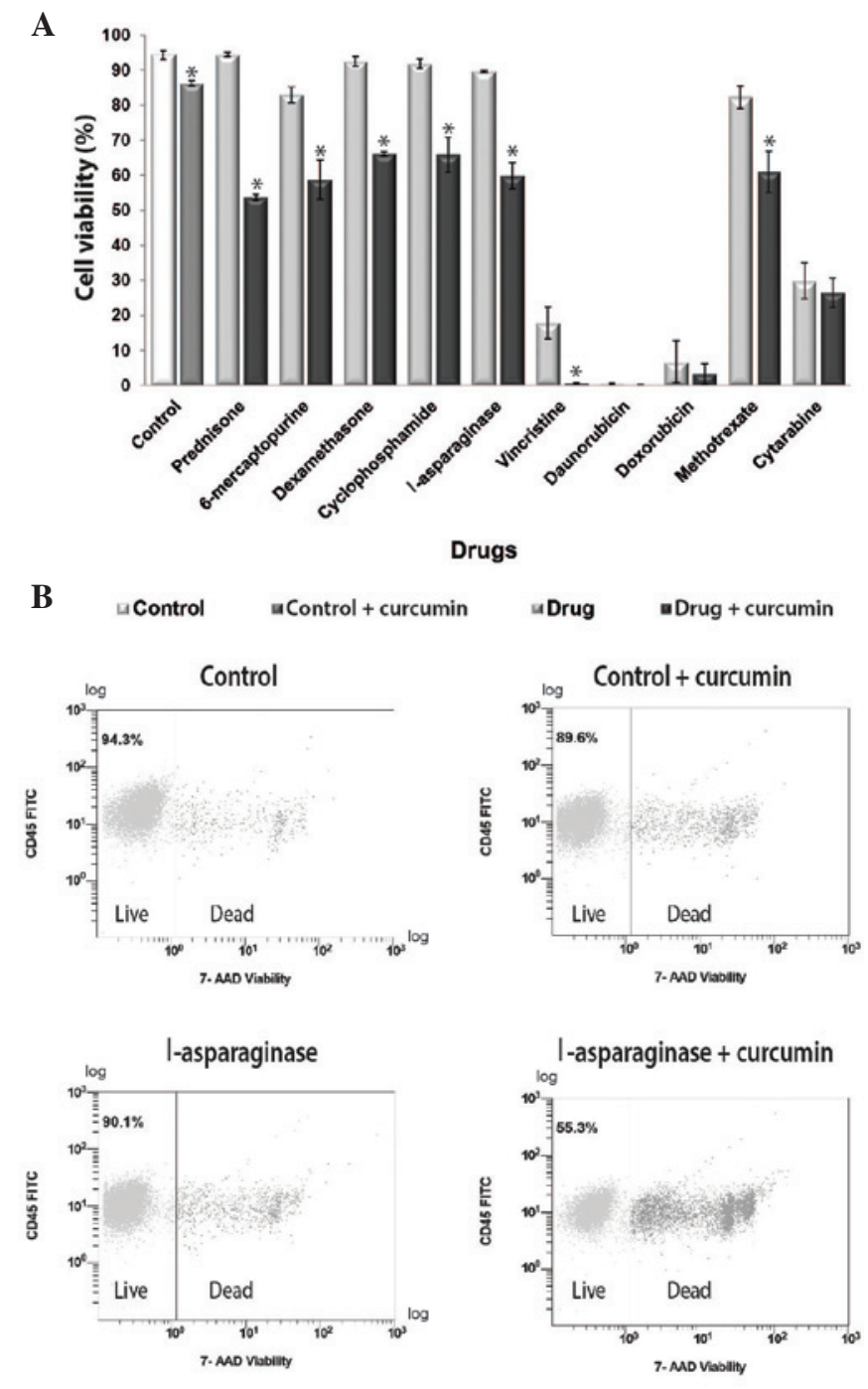

7-AAD (7-amino-actinomycin D) dye exclusion test

Figure 2. Curcumin decreases the viability of the REH cell line following treatment with 10 therapeutic agents. (A) Curcumin decreased cell viability of tumor cells in the 10 groups co-treated with curcumin and chemotherapeutic agents. ${ }^{*} \mathrm{P}<0.05$ vs. control. (B) Treatment with $20 \mu \mathrm{M}$ curcumin decreased cell viability in REH cells, when compared with the 1-asparaginase treatment group. However, cell viability was markedly decreased following combined treatment with curcumin and 1-asparaginase. $\mathrm{CD}$, cluster of differentiation; FITC, fluorescein isothiocyanate; 7-AAD, 7-aminoactinomycin D.

and abnormal cells (15). To determine whether curcumin acts as an antioxidant when combined with chemotherapeutic drugs (16), in the present study, oxidative DNA adduct formation was analyzed in cultures treated with or without curcumin. The results revealed that oxidative DNA adduct formation was decreased in all combined treatment groups, with the exception of the prednisone + curcumin and dexamethasone + curcumin treatment groups. Significant decreases in DNA adduct formation were observed in the groups treated with curcumin and daunorubicin, doxorubicin, methotrexate and cytarabine $(\mathrm{P}<0.05)$ (Fig. 3).

Curcumin decreases NF- $\kappa B$ activation in cells treated with chemotherapeutic agents. It has been reported that constitutive NF- $\mathrm{KB}$ activation occurs in ALL $(7,17)$, and a previous study has suggested that chemotherapy alone may increase this

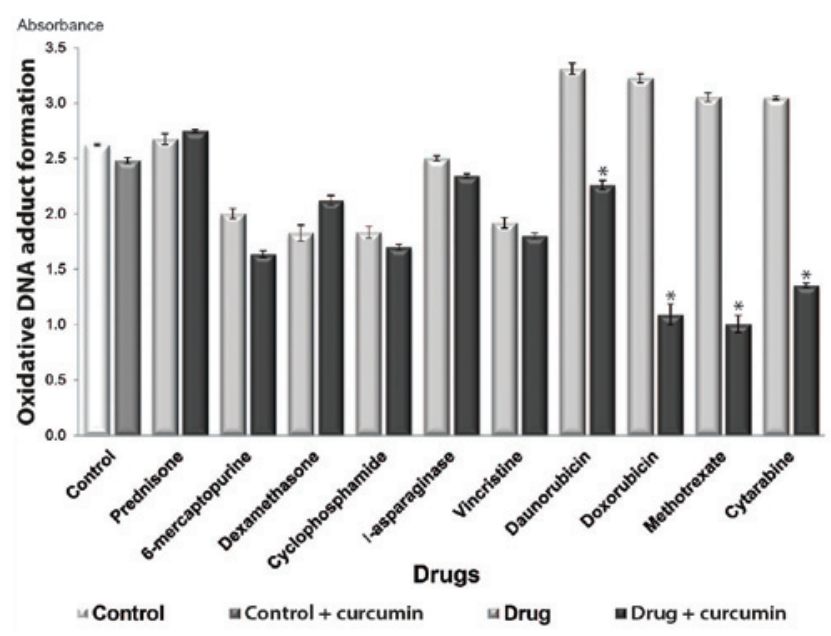

Figure 3. Effect of curcumin on DNA oxidation. Comparison of DNA oxidation in the groups treated with the chemotherapeutic agents alone and in those co-treated with $20 \mu \mathrm{M}$ curcumin. ${ }^{*} \mathrm{P}<0.05$ vs. control.

$\mathbf{A}$

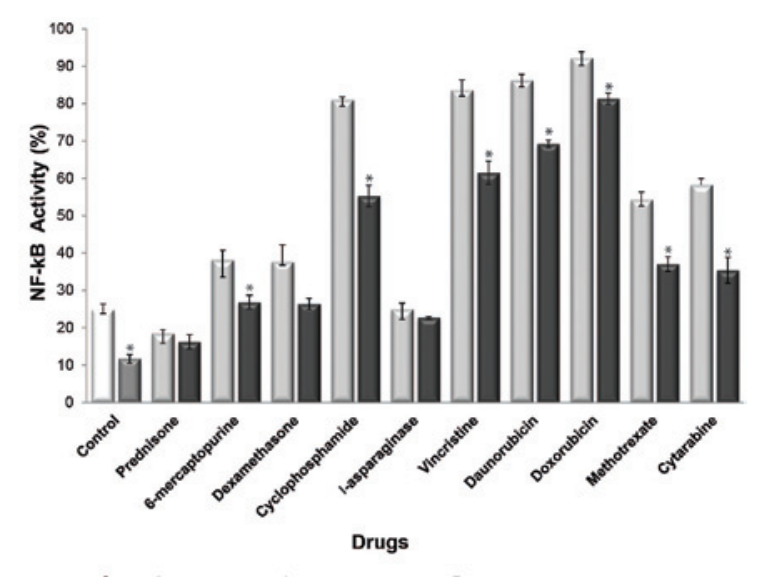

B $u$ Control wControl + curcumin uDrug $\quad$ Drug + curcumin
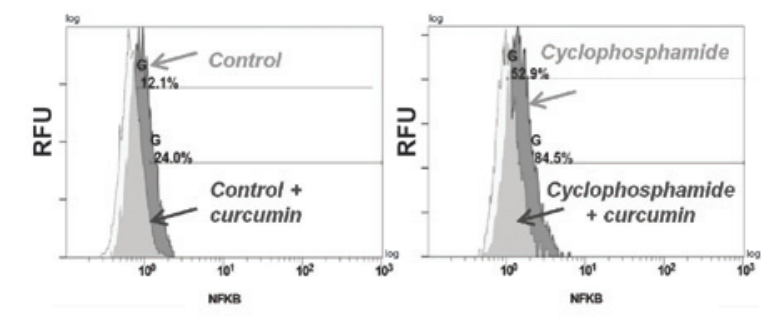

Detection of $N F-\ltimes B$ phosphorylated by flow cylometry

Figure 4. Effect of curcumin and chemotherapy on NF- $\mathrm{kB}$ activity (A) Comparison of NF- $\mathrm{kB}$ activity in the groups treated with chemotherapeutic agents alone and in those co-treated with $20 \mu \mathrm{M}$ curcumin. ${ }^{*} \mathrm{P}<0.05$ vs. control. (B) Treatment with $20 \mu \mathrm{M}$ curcumin increased NF- $\kappa \mathrm{B}$ activity in REH cells, and this increase was most evident in the cyclophosphamide-treated group compared with the cyclophosphamide + curcumin-treated group. NF-кB, nuclear factor-kappa B.

activation (18). To determine whether curcumin decreases the levels of active NF- $\kappa B$ in the REH cell line, the levels of NF- $\mathrm{KB}$ phosphorylated at Ser536 were evaluated by flow cytometry. The results demonstrated that treatment with $8 / 10$ of the therapeutic agents led to increased NF- $\mathrm{kB}$ activity when compared with the control group $(\mathrm{P}<0.05)$, whereas all of the combined treatment groups (chemotherapeutic agent + curcumin) 
A

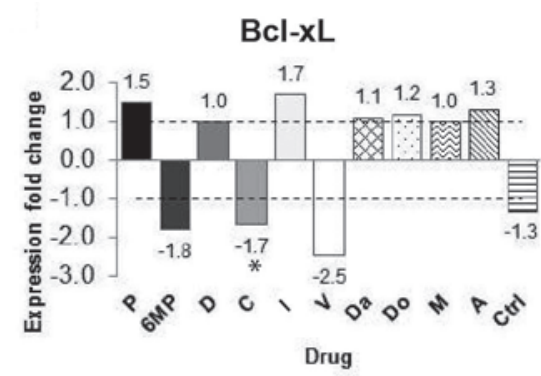

C

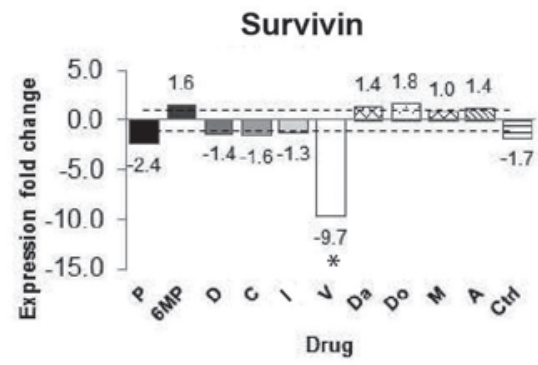

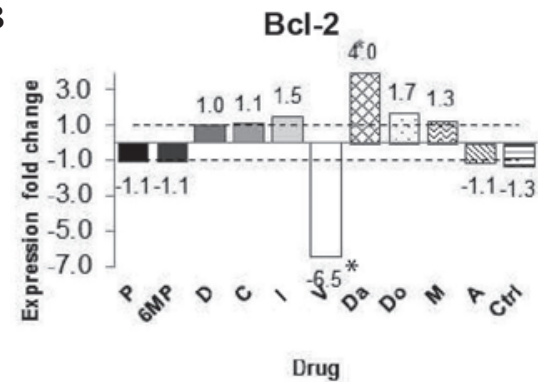

D

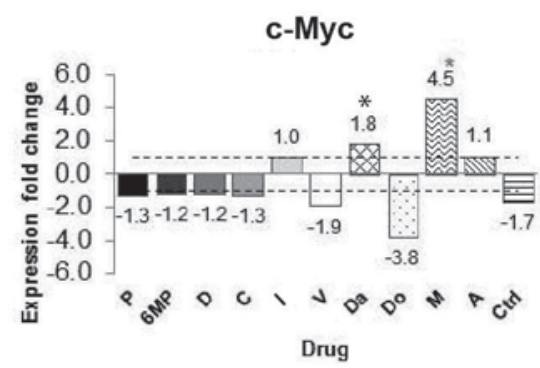

$\mathbf{E}$

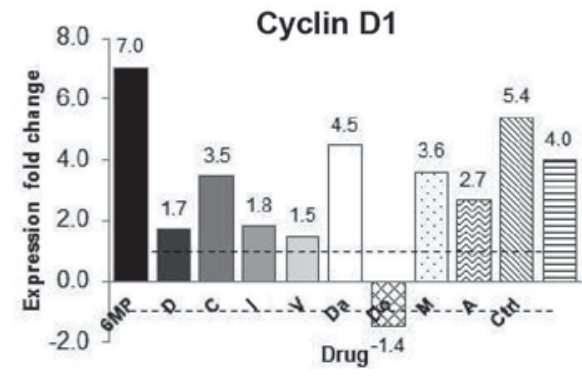

Figure 5. Effect of curcumin on NF- $\mathrm{kB}-$ regulated gene expression. (A) Changes in fold expression of the (A) Bcl-extra large, (B) Bcl-2, (C) survivin, (D) $c-M y c$ and (E) cyclin D1 genes. The data are presented as the fold-change in gene expression between the groups treated with chemotherapy alone and the groups treated with chemotherapy and curcumin. ${ }^{*} \mathrm{P}<0.05$ vs. control. $\mathrm{P}$, prednisone; $6 \mathrm{MP}, 6$-mercaptopurine; $\mathrm{D}$, dexamethasone; $\mathrm{C}$, cyclophosphamide; $\mathrm{L}$, 1-asparaginase; V, vincristine; Da, daunorubicin; Do, doxorubicin; M, methotrexate; A, cytarabine; Ctrl, control; Bcl, B-cell lymphoma; xL, extra large; NF-кB, nuclear factor-kappa B.

exhibited decreased NF- $\kappa$ B activation (Fig. 4A). The control and curcumin alone treatment groups exhibited an NF- $\mathrm{KB}$ activation rate of 24.8 and $11.7 \%$, respectively. The cyclophosphamide treatment group exhibited an NF- $\mathrm{kB}$ activation rate of $81 \%$, while combined treatment with cyclophosphamide and curcumin decreased the NF- $\mathrm{KB}$ activation rate to $55.3 \%$ $(\mathrm{P}<0.05)$ (Fig. 4B). The most significant $\mathrm{NF}-\mathrm{\kappa B}$ inactivation was observed following combined treatment with curcumin and 6-mercaptopurine, cyclophosphamide, vincristine, daunorubicin, doxorubicin, methotrexate and cytarabine $(\mathrm{P}<0.05)$.

Curcumin affects the expression of $N F-\kappa B$ target genes. Since apoptosis and proliferation-related genes $B c l-2, B c l-x l$, survivin, cyclin $D 1$ and $c-M y c$, have all been demonstrated to be regulated by NF- $\kappa \mathrm{B}(19)$, in the present study, the expression of these genes was analyzed. Gene expression was analyzed in the chemotherapy-treated groups with and without curcumin. The gene expression fold change was calculated using the group with chemotherapy without curcumin as calibrator and the chemotherapy with curcumin group as a target group. The gene expression of the anti-apoptosis gene $B c l-x L$ was decreased by 2.5 fold in the vincristine group; however, this difference was not significant ( $\mathrm{P}=0.513$ ) (Fig. 5A). Furthermore,
$B c l-2$ gene expression was decreased by 6.5 fold in the vincristine + curcumin group $(\mathrm{P}<0.05)($ Fig. 5B). The expression of the survivin gene was decreased by 9.7 fold in the vincristine + curcumin group $(\mathrm{P}<0.05)$, when compared with the vincristine group (Fig. 5C). The expression of the proliferative gene $c-M y c$ increased in the methotrexate + curcumin group and decreased by 3.8 fold in the doxorubicin + curcumin group when compared with their calibrator (same chemotherapy without curcumin); however, these changes were not significant $(\mathrm{P}=0.827$ and $\mathrm{P}=0.275$, respectively) (Fig. 5D). Notably, the expression of the cyclin D1 gene was increased in $9 / 10$ of the co-treated groups (with the exception of the doxorubicin group) compared with their calibrator; however, no significant differences were identified (Fig. 5E). These findings indicate that curcumin did not result in a downregulation pattern in the c-Myc and cyclin Dl groups.

Curcumin activates caspase-3. As NF- $\mathrm{KB}$ has been demonstrated to exhibit an anti-apoptosis effect (20), in the present study, the effect of curcumin on apoptosis was investigated. The activity of cleaved caspase-3, the effector protein of the receptor-mediated and chemical-induced apoptosis pathways (21), was evaluated. To determine if curcumin induces 


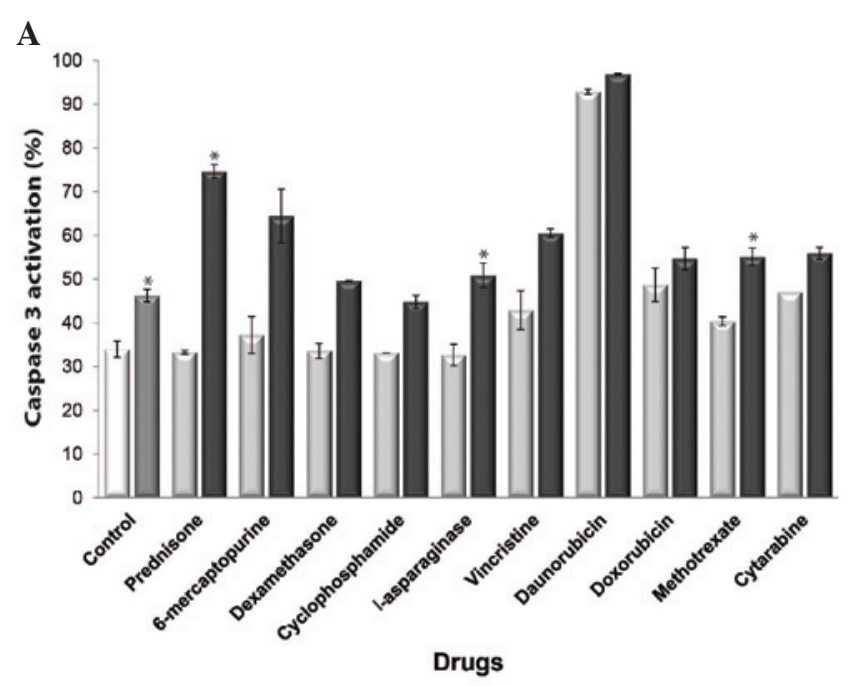

$u$ Control aControl + curcumin aDrug aDrug + curcumin

$\mathbf{B}$

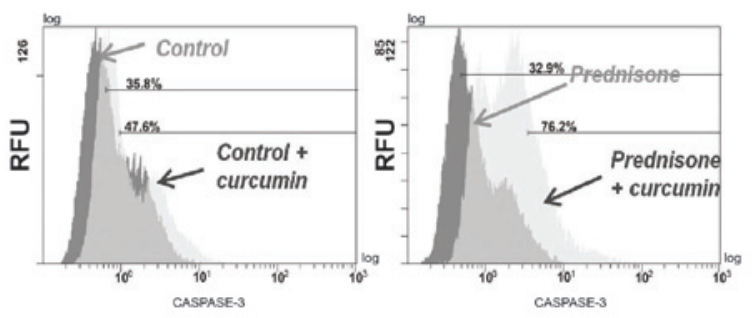

Detection of activated caspase 3 by flow cytometry.

Figure 6. Curcumin induces apoptosis via caspase-3 activation, leading to apoptosis. (A) Caspase-3 activity in the groups treated with chemotherapy alone and co-treated with $20 \mu \mathrm{M}$ curcumin. (B) Curcumin treatment increased caspase- 3 activity in REH cells, which was most evident in the prednisone + curcumin group. ${ }^{*} \mathrm{P}<0.05$ vs. control.

caspase- 3 activation, flow cytometry was performed to analyze the percentage of active caspase- 3 in the chemotherapy-treated cultures with or without curcumin. The results demonstrated that curcumin increased caspase-3 activity following treatment with all the chemotherapeutic agents tested (Fig. 6A). The most significant increases in caspase- 3 activity were identified in the prednisone + curcumin (Fig. 6B), l-asparaginase + curcumin and methotrexate + curcumin groups. However, treatment with curcumin alone also significantly increased caspase- 3 activity $(\mathrm{P}<0.05)$.

\section{Discussion}

In the present study, the effect of curcumin as a phytochemical with chemopreventive and antitumor properties was investigated, as curcumin has been previously used in herbal medicine and as a dietary compound with non-toxic effects (22). The aim of the present study was to evaluate the effect of curcumin in the human ALL REH cell line in combination with a variety of therapeutic agents used to treat ALL. The results revealed that $\mathrm{NF}-\kappa \mathrm{B}$ activation was decreased in all chemotherapeutic agent + curcumin groups, and a subsequent increase in apoptosis was also observed.

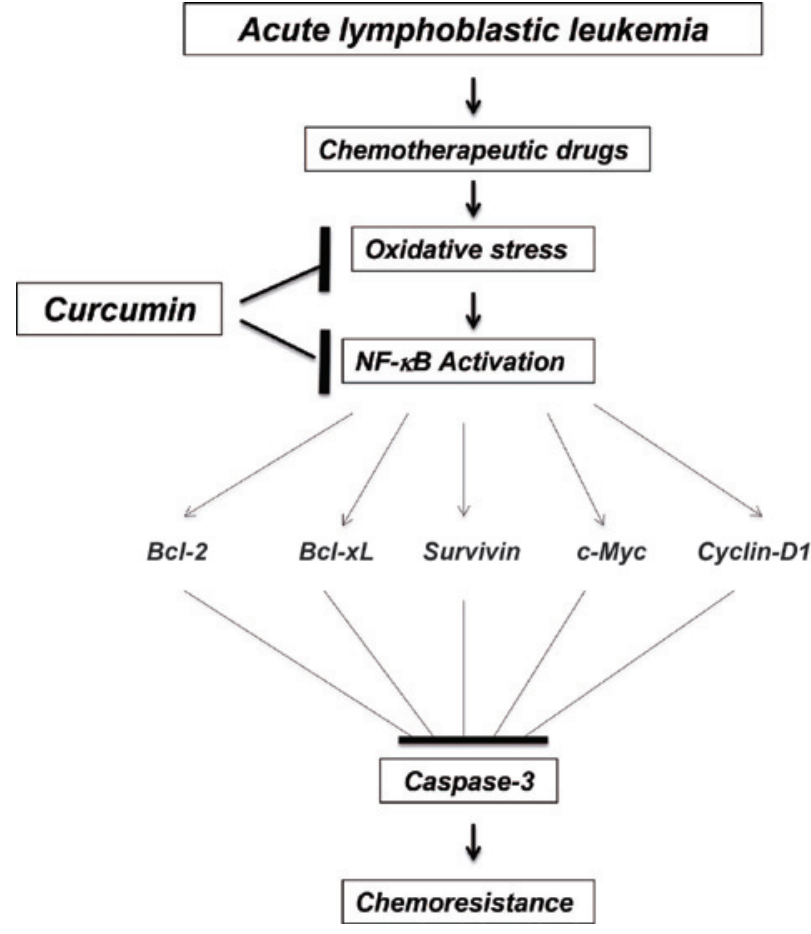

Figure 7. Proposed model of the mechanism of action of curcumin in ALL treatment. In ALL cells, the chemotherapeutic agents cause oxidative stress, which activates the transcription factor $\mathrm{NF}-\kappa \mathrm{B}$ and subsequently leads to the activation of anti-apoptotic and proliferative genes. Consequently, apoptosis is inhibited and chemoresistance is increased. Curcumin decreases the oxidative stress caused by the chemotherapeutic agents and blocks NF- $\mathrm{B}$ activation, consequently increasing apoptosis via caspase- 3 activation, which prevents chemoresistance. NF- $\mathrm{B}$, nuclear factor-kappa B; Bcl, B-cell lymphoma; xL, extra large; ALL, acute lymphoblastic leukemia.

Curcumin was demonstrated to decrease the chemotherapeutic activation of $\mathrm{NF}-\kappa \mathrm{B}$. Previous studies have revealed that chemotherapeutic agents increase $\mathrm{NF}-\kappa \mathrm{B}$ activation (18), while curcumin is able to reduce it (23). In the present study, with the exception of prednisone, treatment with all the chemotherapeutic agents tested resulted in increased $N F-\kappa B$ activation when compared with the control groups. However, treatment with $20 \mu \mathrm{M}$ curcumin downregulated the constitutively active $\mathrm{NF}-\kappa \mathrm{B}$ in the REH cell line, both alone and in combination with all the therapeutic agents tested. It is postulated that this downregulation occurs via activation of the inhibitor of kappa B $\alpha$ (24).

The results of the present study indicate that curcumin functions as a sensitizer in tumor cells and potentiates the antitumor effect of the tested chemotherapeutic agents, as shown by the decreased cell viability observed. Previous evidence that curcumin may potentiate the antitumor effect of chemotherapeutic agents in ALL, was initially observed in ALL-derived Jurkat, REH and RS4;11 cell lines exposed to l-asparaginase and curcumin via inhibition of protein kinase B (AKT) and AKT-regulated gene products (25). In the present study, a decrease in cell viability and an increase in apoptosis was observed following treatment with cyclophosphamide, which was potentiated by curcumin. By contrast, curcumin has been demonstrated to inhibit cyclophosphamide-induced tumor regression in a breast cancer murine model (26). The results of the present study are in 
agreement with previous studies that have demonstrated a decrease in cell viability following curcumin treatment and the synergistic effect of curcumin following co-treatment with 1-asparaginase in leukemia Jurkat, REH and RS4;11 cell lines (25), and vincristine in multiple myeloma cells (27). In the present study, the observed decrease in cell viability following co-treatment with curcumin and vincristine, daunorubicin or doxorubicin was not statistically significant, which may be due to cytotoxicity. Notably, the chemotherapeutic agents in which the decrease in cell viability was most evident in the presence of curcumin exhibited the highest levels of cell viability following treatment with the chemotherapeutic agents alone. Thus, the decrease in cell survival may be attributed to curcumin.

It was also reported that the downregulation of $\mathrm{NF}-\kappa \mathrm{B}$ led to apoptosis of ALL cells, as indicated by the increased expression of the apoptosis effector protein caspase-3 (27). Previously, the antitumoral effect of curcumin was associated with caspase-3 activation (28), and in the present study, all co-treatment groups exhibited an increase in caspase- 3 activity. In contrast to a previous study (29), in the present study, treatment with vincristine alone activated caspase- 3 , and the reported increase in caspase- 3 activity following combined treatment with 1-asparaginase and curcumin was confirmed (30). Notably, in the present study, in the 6-mercaptopurine + curcumin group, the marked increase in caspase-3 activity was not significant, despite the significant decrease in cell viability observed. Therefore, it can be hypothesized that cell death may be activated via an alternative pathway. In the present study, curcumin treatment did not lead to the downregulation of anti-apoptosis and proliferative genes, as previously described (31), indicating that an alternative pathway may be activated, instead of that involving $\mathrm{NF}-\kappa \mathrm{B}$. A previous study revealed that, in AML daunorubicin-resistant cell lines, apoptosis increased following combined treatment with daunorubicin and curcumin (32), and in the present study, an increase in caspase- 3 activity was observed in the daunorubicin and curcumin co-treated cell cultures, although this increase was not statistically significant.

Oxidative stress caused by therapeutic agents used for the treatment of ALL cause damage in non-cancerous tissues (33) leading to the formation of oxidative DNA adducts (34). Curcumin may act as a scavenger of the free radicals caused by the therapy, subsequently reducing these molecules (35). Notably, a previous study revealed that in the NG108-15 (glioblastoma/neuroblastoma hybrid) cell line, curcumin protected the cells from oxidative damage when administered in combination with hydrogen peroxide, but not following pre-treatment (36). In the present study, cell cultures were treated simultaneously with the chemotherapeutic agents and curcumin, which may explain the free radical scavenging properties of curcumin. Notably, not all of the chemotherapeutic agents tested in the present study exhibited increased levels of 8-OHdG when compared with the control group. However, all co-treated groups exhibited a reduction in 8-OHdG molecules compared with the control group, indicating that curcumin controlled the free radicals produced by the therapeutic agents, resulting in less DNA damage. A proposed model that demonstrates the possible mechanism of action of combined treatment with curcumin and chemotherapeutic agents for ALL is shown in Fig. 7.
Clinical studies investigating the efficacy of curcumin for the treatment of pancreatic (37) and colorectal cancer (38) have yielded positive results. However, to the best of our knowledge, no studies have investigated pediatric hematological neoplasias to date. These promising clinical trials in solid tumors, considered together with the decrease in multi-drug resistance gene expression over curcumin in primary ALL cell cultures (39) and potentiation through curcumin of 1-asparaginase (25) correspond to the only studies in vitro, highlighting the importance of the present study. Additional in vitro and mice models to assess the effect of combined treatment with chemotherapeutic agents and curcumin are required. Possible interactions between curcumin at various concentrations and chemotherapeutic agents cannot be excluded and thus, more studies that investigate the possible interactions between curcumin and chemotherapeutic agents are also required.

In conclusion, the present study revealed that curcumin inhibits survival, increases apoptosis and decreases DNA oxidation of REH leukemia cells in an NF- $\kappa \mathrm{B}$-dependent manner, both alone and in combination with all the therapeutic agents tested (prednisone, 6-mercaptopurine, dexamethasone, cyclophosphamide, l-asparaginase, vincristine, daunorubicin, doxorubicin, methotrexate and cytarabine). The application of this compound in the treatment of pediatric lymphoblastic leukemia may improve the outcome of patients. Overall, the present results indicate that curcumin may improve the efficacy of chemotherapeutic agents against ALL.

\section{Acknowledgements}

The authors would like to thank Dr Bharat B. Aggarwal (Cytokine Research Section Department of Molecular Oncology, The University of Texas, M. D. Anderson Cancer Center, Houston, TX, USA) for assistance with the present study, the St. Jude Children's Research Hospital (Memphis, TN, USA) for providing the REH cell line and all the staff members of the Cytogenetics Unit (Pediatric Hematology and Oncology Service, Pediatric Division, Civil Hospital from Guadalajara, Guadalajara, Jalisco, México). The present study was partially supported by the State Council of Science and Technology of Jalisco (Consejo Estatal de Ciencia y Tecnología de Jalisco; Guadalajara, México; grant no. 5-2010-1-1083).

\section{References}

1. Pui CH (ed): Childhood Leukemias. 3rd edition. Cambridge University Press, Cambridge, 2012.

2. Pui $\mathrm{CH}$ and Jeha $\mathrm{S}$ : New therapeutic strategies for the treatment of acute lymphoblastic leukaemia. Nat Rev Drug Discov 6: $149-165,2007$.

3. Libermann TA and Zerbini LF: Targeting transcription factors for cancer gene therapy. Curr Gene Ther 6: 17-33, 2006.

4. Brown M, Cohen J, Arun P, Chen Z and Van Waes C: NF-kappaB in carcinoma therapy and prevention. Expert Opin Ther Targets 12: 1109-1122, 2008.

5. Montagut C, Tusquets I, Ferrer B, Corominas JM, Bellosillo B, Campas C, Suarez M, Fabregat X, Campo E, Gascon P, et al: Activation of nuclear factor-kappaB is linked to resistance to neoadjuvant chemotherapy in breast cancer patients. Endocr Relat Cancer 13: 607-616, 2006.

6. Li F and Sethi G: Targeting transcription factor NF-kappaB to overcome chemoresistance and radioresistance in cancer therapy. Biochim Biophys Acta 1805: 167-180, 2010. 
7. Kordes U, Krappmann D, Heissmeyer V, Ludwig WD and Scheidereit C: Transcription factor NF-kappaB is constitutively activated in acute lymphoblastic leukemia cells. Leukemia 14: 399-402, 2000.

8. Sethi G, Sung B and Aggarwal BB: Nuclear factor-kappaB activation: From bench to bedside. Exp Biol Med (Maywood) 233: 21-31, 2008.

9. Ravindran J, Prasad S and Aggarwal BB: Curcumin and cancer cells: How many ways can curry kill tumor cells selectively? AAPS J 11: 495-510, 2009.

10. Lao CD, Ruffin MT IV, Normolle D, Heath DD, Murray SI, Bailey JM, Boggs ME, Crowell J, Rock CL and Brenner DE: Dose escalation of a curcuminoid formulation. BMC Complement Altern Med 6: 10, 2006.

11. Gupta SC, Kismali G and Aggarwal BB: Curcumin, a component of turmeric: From farm to pharmacy. Biofactors 39 : $2-13,2013$

12. Schmittgen TD and Livak KJ: Analyzing real-time PCR data by the comparative C(T) method. Nat Protoc 3: 1101-1108, 2008.

13. Beillard E, Pallisgaard N, van der Velden VH, Bi W, Dee R, van der Schoot E, Delabesse E, Macintyre E, Gottardi E, Saglio G, et al: Evaluation of candidate control genes for diagnosis and residual disease detection in leukemic patients using 'real-time' quantitative reverse-transcriptase polymerase chain reaction (RQ-PCR) - a Europe against cancer program. Leukemia 17: 2474-2486, 2003.

14. Anand P, Sundaram C, Jhurani S, Kunnumakkara AB and Aggarwal BB: Curcumin and cancer: An 'old-age' disease with an 'age-old' solution. Cancer Lett 267: 133-164, 2008

15. Chen Y, Jungsuwadee P, Vore M, Butterfield DA and St Clair DK: Collateral damage in cancer chemotherapy: Oxidative stress in nontargeted tissues. Mol Interv 7: 147-156, 2007.

16. Blakemore LM, Boes C, Cordell $\mathrm{R}$ and Manson MM: Curcumin-induced mitotic arrest is characterized by spindle abnormalities, defects in chromosomal congression and DNA damage. Carcinogenesis 34: 351-360, 2013.

17. Xue TY, Xu W, An Q, Wu Y, Xu CP and Zhang XY: Expression of nuclear transcription factor kappaB in childhood acute lymphoblastic leukemia and its significance. Zhongguo Shi Yan Xue Ye Xue Za Zhi 15: 767-771, 2007 (In Chinese).

18. Bottero V, Busuttil V, Loubat A, Magné N, Fischel JL, Milano G and Peyron JF: Activation of nuclear factor kappaB through the IKK complex by the topoisomerase poisons SN38 and doxorubicin: A brake to apoptosis in HeLa human carcinoma cells. Cancer Res 61: 7785-7791, 2001.

19. Aggarwal BB and Gehlot P: Inflammation and cancer: How friendly is the relationship for cancer patients? Curr Opin Pharmacol 9: 351-369, 2009.

20. Karin M: NF-kappaB as a critical link between inflammation and cancer. Cold Spring Harb Perspect Biol 1: a000141, 2009.

21. Elmore S: Apoptosis: A review of programmed cell death. Toxicol Pathol 35: 495-516, 2007.

22. Anto RJ, Mukhopadhyay A, Denning K and Aggarwal BB: Curcumin (diferuloylmethane) induces apoptosis through activation of caspase-8, BID cleavage and cytochrome c release: Its suppression by ectopic expression of Bcl-2 and Bcl-xl. Carcinogenesis 23: 143-150, 2002.

23. Shishodia S, Amin HM, Lai R and Aggarwal BB: Curcumin (diferuloylmethane) inhibits constitutive NF-kappaB activation, induces G1/S arrest, suppresses proliferation, and induces apoptosis in mantle cell lymphoma. Biochem Pharmacol 70 $700-713,2005$
24. Kasinski AL, Du Y, Thomas SL, Zhao J, Sun SY, Khuri FR, Wang CY, Shoji M, Sun A, Snyder JP, et al: Inhibition of IkappaB kinase-nuclear factor-kappaB signaling pathway by 3,5-bis(2-flurobenzylidene)piperidin-4-one (EF24), a novel monoketone analog of curcumin. Mol Pharmacol 74: 654-661, 2008.

25. Wang $\mathrm{H}$, Geng QR, Wang L and Lu Y: Curcumin potentiates antitumor activity of L-asparaginase via inhibition of the AKT signaling pathway in acute lymphoblastic leukemia. Leuk Lymphoma 57: 1376-1382, 2012.

26. Somasundaram S, Edmund NA, Moore DT, Small GW, Shi YY and Orlowski RZ: Dietary curcumin inhibits chemotherapy-induced apoptosis in models of human breast cancer. Cancer Res 62: 3868-3875, 2002.

27. Bharti AC, Donato N, Singh S and Aggarwal BB: Curcumin (diferuloylmethane) down-regulates the constitutive activation of nuclear factor-kappa B and IkappaBalpha kinase in human multiple myeloma cells, leading to suppression of proliferation and induction of apoptosis. Blood 101: 1053-1062, 2003.

28. Chan WH, Wu HY and Chang WH: Dosage effects of curcumin on cell death types in a human osteoblast cell line. Food Chem Toxicol 44: 1362-1371, 2006.

29. Al-Katib A, Arnold AA, Aboukameel A, Sosin A, Smith P, Mohamed AN, Beck FW and Mohammad RM: I-kappa-kinase-2 (IKK-2) inhibition potentiates vincristine cytotoxicity in non-Hodgkin's lymphoma. Mol Cancer 9: 228, 2010.

30. Wang H, Geng QR, Wang L and $\mathrm{Lu} \mathrm{Y}$ : Curcumin potentiates antitumor activity of L-asparaginase via inhibition of the AKT signaling pathway in acute lymphoblastic leukemia. Leuk Lymphoma 53: 1376-1382, 2012.

31. Kunnumakkara AB, Anand P and Aggarwal BB: Curcumin inhibits proliferation, invasion, angiogenesis and metastasis of different cancers through interaction with multiple cell signaling proteins. Cancer Lett 269: 199-225, 2008.

32. Rao J, Xu DR, Zheng FM, Long ZJ, Huang SS, Wu X, Zhou WH, Huang RW and Liu Q: Curcumin reduces expression of Bcl-2, leading to apoptosis in daunorubicin-insensitive CD34+ acute myeloid leukemia cell lines and primary sorted CD34+ acute myeloid leukemia cells. J Transl Med 9: 71, 2011.

33. Chen Y, Jungsuwadee P, Vore M, Butterfield DA and St Clair DK: Collateral damage in cancer chemotherapy: Oxidative stress in nontargeted tissues. Mol Interv 7: 147-156, 2007.

34. Valavanidis A, Vlachogianni T and Fiotakis C: 8-hydroxy-2'-deoxyguanosine (8-OHdG): A critical biomarker of oxidative stress and carcinogenesis. J Environ Sci Health C Environ Carcinog Ecotoxicol Rev 27: 120-139, 2009.

35. Thangapazham RL, Sharma A and Maheshwari RK: Multiple molecular targets in cancer chemoprevention by curcumin. AAPS J 8: E443-E449, 2006

36. Mahakunakorn P, Tohda M, Murakami Y, Matsumoto K, Watanabe $\mathrm{H}$ and Vajaragupta $\mathrm{O}$ : Cytoprotective and cytotoxic effects of curcumin: Dual action on $\mathrm{H} 2 \mathrm{O} 2$-induced oxidative cell damage in NG108-15 cells. Biol Pharm Bull 26: 725-728, 2003.

37. Dhillion N, Aggarwal BB, Newman RA, Wolff RA, Kunnumakkara AB, Abbruzzese JL, Ng CS, Badmaev V and Kurzrock R: Phase II trial of curcumin in patients with advanced pancreatic cancer. Clin Cancer Res 14: 4491-4499, 2008.

38. He ZY, Shi CH, Wen H, Li FL, Wang BL and Wang J: Upregulation of p53 expression in patients with colorectal cancer by administration of curcumin. Cancer Invest 29: 208-213, 2011.

39. Anuchapreeda S, Thanarattanakorn P, Sittipreechacharn S, Tima S, Chanarat P and Limtrakul P: Inhibitory effect of curcumin on MDR1 gene expression in patient leukemic cells. Arch Pharm Res 29: 866-873, 2006. 